Arq. Bras. Med. Vet. Zootec., v.57, n.5, p.576-583, 2005

\title{
Morcegos capturados no município de Belo Horizonte, 1999-2003
}

[Bats found in the city of Belo Horizonte, MG, 1999-2003]

\author{
L.V. De Knegt ${ }^{1 *}$, J.A. Silva ${ }^{2}$, E.C. Moreira ${ }^{2}$, G.L. Sales ${ }^{3}$ \\ ${ }^{1}$ Aluno de mestrado - Escola de Veterinária da UFMG - Belo Horizonte \\ ${ }^{2}$ Departamento de Medicina Veterinária Preventiva - Escola de Veterinária da UFMG - Belo Horizonte \\ ${ }^{3}$ Aluno de Mestrado - Pontifícia Universidade Católica de Minas Gerais - Belo Horizonte
}

\begin{abstract}
RESUMO
Entre os anos de 1999 e 2001, realizaram-se 18 capturas de morcegos em Belo Horizonte, sendo uma na estação seca e uma na estação chuvosa em cada regional administrativa. Foram capturados 316 exemplares, com predominância de Artibeus lituratus (Olfers, 1818), 55,1\%, Platyrrhinus lineatus (Geoffroy, 1810), 24,4\% e Glossophaga soricina (Pallas, 1766), 10,1\%, além de Sturnira lilium (Geoffroy, 1810), Phyllostomus discolor (Wagner, 1843), Carollia perspicillata (Linnaeus, 1758), Myotis nigricans (Schinz, 1821) e Anoura caudifer (Geoffroy, 1818), totalizando oito espécies, pertencentes às famílias Phyllostomidae e Vespertilionidae. Observou-se concentração de partos próximos à estação chuvosa, coincidindo com a maior disponibilidade de alimento para os períodos de prenhez e lactação. Partos esporádicos ocorreram durante todo o ano. Entre 2002 e 2003, foi feita uma busca em diversos tipos de abrigos nas mesmas regionais. Os abrigos foram registrados, e as espécies encontradas foram somadas às já observadas na primeira parte deste estudo, bem como às citadas em diversas fontes bibliográficas e disponíveis em coleções acadêmicas, gerando um relato atualizado das espécies de morcegos já encontrados no município.
\end{abstract}

Palavras-chave: morcego, Chiroptera, epidemiologia, reprodução, abrigo

\begin{abstract}
A total of 316 bats were trapped using mist nets during 18 nights at nine strategic locations in Belo Horizonte between 1999 and 2001. The most predominant species were Artibeus lituratus (Olfers, 1818), $55.1 \%$, Platyrrhinus lineatus (Geoffroy, 1810), 24.4\%, and Glossophaga soricina (Pallas, 1766), 10.1\%. Other trapped species were: Sturnira lilium (Geoffroy, 1810), Phyllostomus discolor (Wagner, 1843), Carollia perspicillata (Linnaeus, 1758), Myotis nigricans (Schinz, 1821) and Anoura caudifer (Geoffroy, 1818), resulting in a total of eight species belonging the families Phyllostomidae and Vespertilionidae. All species bred predominantly during the wet season, probably because of the need for food availability to support energetic demands during pregnancy and lactation. However, all species bred at other times of the year as well. An updated list of bat species found in Belo Horizonte was prepared which included those observed in the first part of this study, those cited in scientific papers and academic collections and those recorded in additional observations during 2002 and 2003.
\end{abstract}

Keywords: bat, chiroptera, trapping, reproduction, roost

Recebido para publicação em 19 de maio de 2004

Recebido para publicação, após modificações, em 6 de novembro de 2004

*Endereço para correspondência (corresponding address)

Rua Jacarandá, 238 - Condomínio Serra dos Manacás

34000-000 - Nova Lima, MG

E-mail: chorse@terra.com.br 


\section{INTRODUÇÃ̃O}

Levantamento de espécies de morcegos não é novidade, no entanto, poucos estudos foram feitos em áreas completamente antrópicas, como na zona urbana de grandes cidades. Estudos foram feitos em áreas limitadas de Belo Horizonte, como o Parque Municipal Fazenda Lagoa do Nado, o Jardim Zoológico (Dias, 1995) e a Estação Ecológica da UFMG (Sánchez, 2001), mas ainda não há um estudo que cubra toda a área do município.

A metodologia de redes de neblina favorece apenas a captura de filostomídeos (Tavares, 1999; Sánchez, 2001), pois embalonurídeos e molossídeos geralmente voam acima do dossel, vespertilionídeos teriam a capacidade de detectar as redes através de ecolocação, e outras espécies costumam forragear sobre a água, de forma que uma composição de espécies completa só poderia ser realizada utilizando várias metodologias.

Na maioria das plantas, a floração ocorre na estação seca (Sánchez, 2001), e a frutificação, na estação chuvosa. Sánchez (2001) observou queda na produtividade de frutos durante a estação seca, mas comenta que, apesar disso, na zona tropical, frutos maduros estão disponíveis durante todo o ano. Heithaus et al. (1975) comentam que a distribuição e a disponibilidade de recursos alimentares influenciam o comportamento reprodutivo dos quirópteros.

Segundo Kunz et al. (1998), a gravidez e a lactação são os períodos de maior exigência energética. Zortéa (2003) afirma que os ciclos reprodutivos dos quirópteros estão associados à estação chuvosa, com a maioria das espécies de morcegos neotropicais apresentando ciclo reprodutivo biestral, com concentração de partos na estação chuvosa ou logo antes desta. Isso condiz com a observação de Tavares (1999) de que os picos reprodutivos ocorrem em períodos de alta umidade. Heithaus et al. (1975) observaram dois partos por ano em A. lituratus, G. soricina, C. perspicillata e S. lilium, sendo o primeiro entre o meio e o final da estação seca, coincidindo com o pico de floração, e o segundo no início das chuvas, no auge das frutificações. O mesmo foi observado por Zortéa (2003), que justifica essa concentração pela maior disponibilidade de alimento, favorecendo a sobrevivência das crias.
Os molossídeos são os quirópteros com maior capacidade de adaptação a ambientes urbanos. Isto se observa particularmente em Molossus molossus e Molossus ater, que utilizam juntas de dilatação entre edifícios como abrigo (Bredt e Uieda, 1996; Silva et al., 1996). Esberárd et al. (1999) afirmam que, das 18 espécies de morcegos que utilizam construções como abrigo no Rio de Janeiro, as mais comuns pertencem às famílias Molossidae e Vespertilionidae, também sendo encontrados representantes de Phyllostomidae e Noctilionidae. Bredt e Uieda (1996) descrevem que copas de árvores são utilizadas como abrigo por Artibeus lituratus e Platyrrhinus lineatus. Silva et al. (1996) citam essa utilização por $A$. lituratus e comentam a preferência de Glossophaga soricina por forros e construções vazias. As mais variadas preferências por abrigos foram citadas por Uieda e Hayashi (1996), Césari (1996), Esberárd et al. (1999), de acordo com a espécie.

O presente estudo teve o objetivo de verificar a ocorrência e a distribuição das espécies de quirópteros no município de Belo Horizonte, analisar seu comportamento reprodutivo durante $o$ ano e averiguar sua presença em diferentes abrigos criados pelo homem.

\section{MATERIAL E MÉTODOS}

Belo Horizonte possui aproximadamente 500 praças e 27 parques e conta com um sistema de arborização urbana que utiliza aproximadamente 80 espécies vegetais (Toledo, 1993), fazendo com que haja áreas de vegetação variada distribuídas por todo o município. Isso permite que vários animais silvestres, dentre eles os quirópteros, ainda encontrem na cidade um ambiente adequado à sobrevivência.

O clima local atinge as maiores temperaturas, juntamente com os maiores índices pluviométricos, durante os meses de outubro a março, caracterizando uma estação quentechuvosa. A estação mais fria e seca ocorre nos seis meses restantes (Balanço... 2000).

A cidade divide-se em nove regionais administrativas. Elas foram adotadas como forma de padronização e de referência para cobertura de área, de forma que todas foram visitadas durante 
o desenvolvimento da pesquisa, garantindo uma cobertura amostral de todo o município.

A primeira parte do estudo foi realizada entre os anos de 1999 e 2001. Escolheu-se um local de coleta em cada regional que foi visitado duas vezes, uma na estação fria-seca e outra na quente-chuvosa. Foram utilizadas duas redes de 6 $\times 2,5 \mathrm{~m}$ e uma rede de $12 \times 3 \mathrm{~m}$ em cada uma das coletas, que transcorreram entre 19 e $2 \mathrm{~h}$, totalizando um esforço de coleta de 126 horas, com área total de rede de $918 \mathrm{~m}^{2}$.

Foi feita uma caracterização histórica, geográfica e botânica de cada área visitada, de forma a verificar a ocorrência de condições favoráveis ou plantas úteis aos quirópteros, seja como fonte de abrigo ou alimentação (De Knegt, 2003).

Os exemplares foram identificados com relação à espécie, sexo, idade e condição reprodutiva. Os indivíduos foram incluídos nas categorias relacionadas à idade, com base no tamanho, pelagem, desgaste dos dentes e ossificação das epífises das asas (Dinerstein, 1986), sendo classificados como filhotes, jovens ou adultos. A identificação da condição reprodutiva foi feita levando-se em conta as seguintes categorias: macho jovem, macho com testículo intraabdominal, macho com testículo exposto, fêmea não-reprodutiva, fềmea jovem, fêmea grávida e fêmea lactante. Além disso, devido a problemas na identificação de alguns indivíduos, foram criadas as categorias não-determinado, para espécimes não-identificados quanto ao sexo, e macho não-determinado, para os machos cuja condição reprodutiva ou idade não foi visualizada.

Para buscar espécies que não eram passíveis de captura pela metodologia anterior, foram feitas coletas em abrigos diurnos. As buscas foram feitas em forros, telhados, sótãos, juntas de dilatação, porões e algumas copas e ocos de árvores. Como na fase anterior, as buscas foram feitas em pelo menos um local de cada regional, sendo que, por maior ou menor disponibilidade de locais, algumas regionais foram visitadas mais de uma vez. Nos locais eleitos, foi feita a tentativa de visualização de quirópteros, vestígios ou condições indicativas de sua presença (guano nas paredes ou no chão, espaço para vôo dentro do possível abrigo e aberturas para entrada e saída). Uma vez localizados, os indivíduos foram fotografados e capturados com o auxílio de puçás ou redes de neblina. Em alguns casos, não houve condições físicas ou estruturais que permitissem a captura, não tendo sido possível identificar, portanto, a espécie da colônia observada. Em outros casos, foi possível obter fotografias digitais que, ampliadas, permitiram a identificação até de família ou de gênero, dependendo do caso. Foram também acolhidos como dados para a pesquisa morcegos levados à Escola de Veterinária ou encontrados mortos em ruas e construções.

$\mathrm{Na}$ busca por abrigos, foram verificados 32 forros, 42 telhados, seis torres de igreja, uma junta de dilatação, sete cômodos e 18 áreas externas.

Um indivíduo de cada sexo por espécie coletada foi sacrificado em câmara de éter como testemunha de captura de sua espécie. Os espécimes sacrificados foram fixados em formol $5 \%$ e conservados em álcool $70 \%$.

A identificação dos morcegos foi feita pelo uso de chaves (Vizotto e Taddei, 1973; Baker et al., 1976; Reis et al., 1993; Emmons, 1997).

\section{RESULTADOS E DISCUSSÃO}

O resultado das capturas pode ser observado na Tab. 1.

A maior captura de filostomídeos justifica-se pela metodologia utilizada e, também, pelo fato de a família ser a que apresenta maior variedade de espécies (Tavares, 1999; Falcão et al., 2003). Além disso, famílias como Molossidae, Emballonuridae e a própria Vespertilionidae apresentam características de vôo que dificultam ou não permitem sua captura pela metodologia citada (Tavares, 1999). 
Morcegos capturados...

Tabela 1. Número de morcegos capturados segundo a espécie e a região administrativa, Belo Horizonte, 1999-2001

\begin{tabular}{|c|c|c|c|c|c|c|c|c|c|c|c|}
\hline \multirow{2}{*}{ Família } & \multirow{2}{*}{ Espécie } & \multicolumn{10}{|c|}{ Regional } \\
\hline & & $\mathrm{NE}$ & $\mathrm{NO}$ & $\mathrm{PA}$ & $\mathrm{O}$ & $\mathrm{VN}$ & $\mathrm{BA}$ & $\mathrm{CS}$ & LE & NR & Total \\
\hline \multirow[b]{4}{*}{ Phyllostomidae } & Artibeus lituratus & 15 & 4 & 30 & 11 & 20 & 33 & 24 & 19 & 18 & 174 \\
\hline & Platyrrhinus lineatus & 4 & 0 & 3 & 4 & 2 & 32 & 20 & 1 & 11 & 77 \\
\hline & Glossophaga soricina & 5 & 0 & 2 & 0 & 1 & 9 & 9 & 0 & 6 & 32 \\
\hline & Sturnira lilium & 0 & 0 & 6 & 0 & 9 & 0 & 0 & 0 & 0 & 15 \\
\hline \multirow{6}{*}{ Vespertilionidae } & Phyllostomus discolor & 0 & 1 & 3 & 0 & 1 & 0 & 0 & 8 & 0 & 13 \\
\hline & Carollia perspicillata & 0 & 0 & 0 & 0 & 2 & 0 & 0 & 0 & 1 & 3 \\
\hline & Anoura caudifer & 0 & 0 & 0 & 0 & 0 & 0 & 1 & 0 & 0 & 1 \\
\hline & Myotis nigricans & 0 & 0 & 0 & 0 & 1 & 0 & 0 & 0 & 0 & 1 \\
\hline & Total & 24 & 5 & 44 & 15 & 36 & 74 & 54 & 28 & 36 & 316 \\
\hline & Porcentagem & 7,60 & 1,60 & 13,90 & 4,75 & 11,40 & 23,40 & 17,10 & 8,85 & 11,40 & 100 \\
\hline
\end{tabular}

Observa-se predominância de Artibeus lituratus $(55,1 \%)$ por ser o filostomídeo mais abundante em ambientes urbanos (Tavares, 1999). Tipo de abrigo, tamanho das colônias e características de alimentação justificam essa predominância. A espécie é considerada frugívora generalista, mas alimenta-se também de insetos, pólen e néctar e usa até fração de folhas como fonte adicional de alimento (Kunz e Diaz, 1995).

O segundo maior número de capturas foi de Platyrrhinus lineatus, um filostomídeo com hábitos alimentares e de abrigo muito semelhantes. Observa-se que todas as espécies vegetais citadas por Tavares (1999) e Sánchez (2001) como fonte primária de alimento para $P$. lineatus são plantas utilizadas no sistema de arborização viária de Belo Horizonte (Toledo, 1993), o que constitui um ambiente altamente favorável à sua manutenção.

O terceiro maior número de capturas, Glossophaga soricina $(10,1 \%)$, espécie que se adaptou bem aos abrigos urbanos, foi encontrada em telhados, forros, porões, depósitos, cisternas e casas de bombas. Sua abundância na Regional Centro-Sul provavelmente está relacionada ao fato de a região apresentar jardins combinados de forma a florescer seqüencialmente, o que garante alimento durante todo o ano. Ocorrem também em pátios e pomares contendo frutos para a espécie, como Fícus sp. (Zortéa, 1993) e Psidium guajava (Sánchez, 2001). Segundo Willig et al. (1993), isso já seria um fator de manutenção dos glossofagíneos, que, apesar de adaptados à nectarivoria, podem agir como frugívoros ou insetívoros.

Sturnira lilium foi capturado apenas nas
Regionais Pampulha e Venda Nova, captura já observada por Sánchez (2001), e está relacionada à presença de diversas árvores frutíferas e arbustos floríferos úteis para a espécie (De Knegt, 2003). Na Regional Venda Nova ocorrem espécies vegetais que poderiam servir como fonte de pólen e néctar, ou como atrativo para insetos, a fonte primária de alimento dessa espécie (Heithaus et al., 1975; Falcão et al., 2003).

Phillostomus discolor foi capturado nas Regionais Pampulha, Noroeste, Venda Nova e Leste. Todos os indivíduos da espécie foram capturados na estação chuvosa, o que contraria a suposição de Heithaus et al. (1975) de que $P$. discolor alimenta-se primariamente de néctar, encontrado mais disponível durante a estação seca (Sánchez, 2001). Além disso, esses achados estão de acordo com os autores que o classificaram como insetívoro, já que os insetos são mais abundantes durante a estação chuvosa (Willig et al., 1993). Na Regional Leste, área do horto e de jardins, encontram-se pelo menos duas espécies vegetais citadas pela bibliografia como fontes de alimento para $P$. discolor (Sazima e Sazima, 1977). Durante a captura, observou-se que os exemplares dessa espécie alimentavam-se de uma piperácea, cuja identificação não foi levada adiante.

Carollia perspicillata foi encontrado nas Regionais Venda Nova e Norte, e sua presença em áreas de degradação média está de acordo com Tavares (1999). As considerações a respeito da Regional Venda Nova feitas para S. lilium estendem-se a esta espécie. Na Regional Norte, o ambiente oferece diversas árvores frutíferas 
nativas e exóticas, vários tipos de flores e boas condições para a proliferação de insetos, o que forneceria alimento suficiente e variado para uma espécie de hábito generalista (Willig et al., 1993; Emmons, 1997). Apesar de plantas do gênero citado não terem sido encontradas na área, o local poderia servir apenas como abrigo da espécie, acostumada a voar grandes distâncias a partir do seu abrigo (Fleming e Heithaus, 1986).

Apesar das semelhanças morfológicas e ecológicas entre $C$. perspicillata e $S$. lilium (Heithaus et al., 1975; Muller e Reis, 1992), que freqüentemente resultam em coexistência das duas espécies em uma mesma área, isso só foi observado na Regional Venda Nova.

As duas espécies restantes são consideradas válidas como parte do levantamento de espécies, mas não constituem uma amostra razoável para análises de população.

O maior número de espécies encontradas na Regional Venda Nova deve-se, provavelmente, à tranqüilidade e ao baixo grau de intromissão humana na área (subúrbios), mesmo sabendo-se que a região não oferece variedade de alimento favorável à manutenção de muitas espécies.

O maior número de indivíduos das três espécies mais observadas foi capturado no Barreiro. A área, um terreno reflorestado, com um pomar no meio da zona residencial/industrial, oferece alimento para frugívoros pouco seletivos e nectarívoros, o que provavelmente resultou na maior concentração de morcegos nos horários de alimentação.

Fatores semelhantes concorreram para a alta concentração das mesmas espécies no local de coleta da Regional Centro-Sul. A vegetação na área é composta por uma seleção que, por motivos estéticos, apresenta plantas em frutificação ou florescimento durante todo o ano.

Observa-se a captura de exatamente o dobro de indivíduos de $A$. lituratus na estação seca em relação à chuvosa, (Tab. 2). A captura de maior número de fêmeas grávidas na seca e de lactantes na chuvosa está de acordo com Heithaus et al. (1975) e Tavares (1999) em relação à parição na estação chuvosa, se se considerar o período de gestação de quatro meses (Tamsitt e Valdivieso, 1963). Todas as categorias reprodutivas foram capturadas nas duas estações, desse modo, percebe-se que os partos ocorrem durante todo o ano, observação semelhante à de Duarte (2003). Portanto, a espécie seria poliéstrica não-sazonal.

Tabela 2. Número de morcegos capturados segundo a espécie e a categoria reprodutiva nas estações seca (S) e chuvosa (C), Belo Horizonte, 1999-2001

\begin{tabular}{|c|c|c|c|c|c|c|c|c|c|c|c|c|c|c|c|c|c|c|c|c|}
\hline & \multicolumn{10}{|c|}{ Espécies } & \multicolumn{10}{|c|}{ Categorias reprodutivas } \\
\hline & \multicolumn{2}{|c|}{ MND } & \multicolumn{2}{|c|}{ MJ } & \multicolumn{2}{|c|}{ MTIA } & \multicolumn{2}{|c|}{ MTE } & \multicolumn{2}{|c|}{$\mathrm{F}$} & \multicolumn{2}{|c|}{ FJ } & \multicolumn{2}{|c|}{ FGR } & \multicolumn{2}{|c|}{ FLC } & \multicolumn{2}{|c|}{ N.D. } & \multicolumn{2}{|c|}{ Total } \\
\hline & $\mathrm{S}$ & $\mathrm{C}$ & $\mathrm{S}$ & $\mathrm{C}$ & $\mathrm{S}$ & $\mathrm{C}$ & $\mathrm{S}$ & $\mathrm{C}$ & $\mathrm{S}$ & $\mathrm{C}$ & $\mathrm{S}$ & $\mathrm{C}$ & $\mathrm{S}$ & $\mathrm{C}$ & $\mathrm{S}$ & $\mathrm{C}$ & $\mathrm{S}$ & $\mathrm{C}$ & $\mathrm{S}$ & $\mathrm{C}$ \\
\hline A. lituratus & 0 & 0 & 5 & 2 & 18 & 4 & 31 & 30 & 31 & 10 & 5 & 2 & 21 & 1 & 3 & 9 & 2 & 0 & 116 & 58 \\
\hline P. lineatus & 0 & 3 & 0 & 1 & 5 & 7 & 4 & 10 & 5 & 19 & 2 & 2 & 3 & 3 & 0 & 3 & 10 & 0 & 29 & 48 \\
\hline G. soricina & 0 & 3 & 1 & 4 & 2 & 3 & 3 & 1 & 2 & 4 & 0 & 1 & 2 & 4 & 0 & 1 & 0 & 1 & 10 & 22 \\
\hline S. lilium & 0 & 0 & 0 & 0 & 0 & 3 & 1 & 4 & 1 & 3 & 0 & 3 & 0 & 0 & 0 & 0 & 0 & 0 & 2 & 13 \\
\hline P. discolor & 0 & 0 & 0 & 0 & 0 & 6 & 0 & 1 & 1 & 4 & 0 & 0 & 0 & 1 & 0 & 0 & 0 & 0 & 1 & 12 \\
\hline C. perspicillata & 0 & 0 & 0 & 0 & 0 & 1 & 0 & 1 & 0 & 1 & 0 & 0 & 0 & 0 & 0 & 0 & 0 & 0 & 0 & 3 \\
\hline M. nigricans & 0 & 0 & 0 & 0 & 0 & 0 & 0 & 0 & 0 & 0 & 0 & 0 & 1 & 0 & 0 & 0 & 0 & 0 & 1 & 0 \\
\hline A. caudifer & 0 & 0 & 0 & 0 & 0 & 0 & 0 & 1 & 0 & 0 & 0 & 0 & 0 & 0 & 0 & 0 & 0 & 0 & 0 & 1 \\
\hline Total & 0 & 6 & 6 & 7 & 25 & 24 & 39 & 48 & 40 & 41 & 7 & 8 & 27 & 9 & 3 & 13 & 12 & 1 & 159 & 157 \\
\hline
\end{tabular}

MND = macho não-determinado; MJ = macho jovem; MTIA = macho com testículos intra-abdominal; MTE = macho com testículos expostos; F = fêmea não reprodutiva; FJ = fêmea jovem; FGR = fêmea grávida; FLC = fêmea lactante; ND = nãodeterminado.

A captura de maior número de indivíduos de $P$. lineatus ocorreu na estação chuvosa. A concentração de grupos específicos na seca foi observada em machos jovens, machos com testísculos intra-abdominal, machos com testículos expostos, fêmeas não-reprodutivas e fêmeas lactantes. Fêmeas grávidas e fêmeas jovens foram capturadas em quantidades iguais nas duas estações. Não foram encontrados na bibliografia dados suficientes para discutir os resultados observados. 
O número de capturas de G. soricina, do ponto de vista reprodutivo, é semelhante ao apresentado por Zortéa (2003). Foi capturado maior número de fêmeas grávidas na estação chuvosa, o que está de acordo com Tavares (1999). A única fêmea lactante da espécie foi capturada no mês de fevereiro. Em relação aos machos, e também de acordo com Zortéa (2003), maior número de capturas de machos em reprodução ocorreu na estação seca.

Nenhuma fêmea grávida ou lactante de S. lilium foi capturada, e a maioria das capturas ocorreu na estação chuvosa, sugerindo um pico da população nessa época. Esse resultado está de acordo com o de Sánchez (2001). Segundo esse autor, o pico ocorreu com o aumento da frutificação.

Em relação a $P$. discolor, a concentração de capturas ocorreu na estação chuvosa. Esse fato está de acordo com a suposição de Heithaus et al. (1975), de que a espécie tende a migrar na estação seca, em busca de áreas com maior disponibilidade de alimento. A distribuição segundo a categoria reprodutiva no período chuvoso sugere que a espécie seja monoestral, por apresentar uma possível concentração da reprodução no período de seca, aspecto já sugerido por Heithaus et al. (1975). Contudo, os resultados discordam dos apresentados pelos autores quanto à época de ocorrência dos partos. Essa hipótese está de acordo com a nectarivoria, citada por Heithaus et al. (1975) e Sazima e Sazima (1977), e com a maior disponibilidade de flores na seca (Sánchez, 2001; Zortéa, 2003). C. perspicillata, $M$. nigricans e $A$. caudifer não foram capturados em número suficiente de indivíduos para permitir qualquer tipo de análise.

O número de capturas segundo a espécie e o abrigo encontra-se na Tab. 3.

Além de algumas espécies já citadas na Tab. 1, foram também encontradas as espécies Rynchonyeteris naso (família Eniballonuridae), Tadaria brasiliensis e Molossus molossus (família Molossidae).

Tabela 3. Número de espécies de morcegos capturados segundo o abrigo, Belo Horizonte, 2002-2003

\begin{tabular}{lccc}
\hline Família & Espécie & Estrutura & Número \\
\hline \multirow{3}{*}{ Phyllostomidae } & A. lituratus & Copa de árvores & 1 a 7 \\
& P. lineatus & Marquise & 3 a 9 \\
Emballonuridae & F. soricina & Forro & 4 a 6 \\
& C. perspicillata & Forro & 10 \\
Molossidae & R. naso & Forro & 1 \\
& T. brasiliensis & Cômodo & 1 \\
& Molossus sp. & Telhado & 2 \\
& Não-identificado & Junta de dilatação & Não contado \\
\hline
\end{tabular}

Todos os indivíduos do gênero Artibeus foram observados em árvores (Tab. 3), o que dificultou sua identificação. Entretanto, é provável que pertençam à espécie $A$. lituratus, por sua abundância na região, já discutida anteriormente. Essa preferência por árvores em meio a construções é bastante comum para a espécie, aspecto já observado por Césari (1996) e Silva et al. (1996). Dois grupos de P. lineatus foram observados na marquise de uma igreja e sob uma projeção de concreto no alto de um edifício, ambos na Regional Centro-Sul. A presença da espécie em marquises, por sua semelhança estrutural com toldos e peitoris, está de acordo com o observado no Rio de Janeiro por Esberárd et al. (1999). C. perspicillata foi encontrado habitando uma câmara sobre a cúpula de uma igreja na Regional Noroeste. Quatro G. soricina foram encontrados sob o telhado de uma escola na Regional Centro-Sul. A presença deles em forros é bastante freqüente (Silva et al., 1996). Césari (1996) considera os forros como a primeira escolha de abrigo urbano para a espécie. No mesmo telhado, bastante próximo ao grupo citado, foram observados e coletados dois indivíduos de Molossus sp. nos espaços entre os caibros, no rejunte de concreto e na parede de tijolos. A ocorrência de molossídeos nesses locais é bastante comum nas grandes cidades (Silva et al., 1996; Esberárd et al., 1999). Curiosamente, apenas nesse local foi encontrada essa família nas condições descritas na 
bibliografia. Em um hospital na Regional Centro-Sul foi encontrada uma colônia de $G$. soricina na sala de manutenção. A captura da espécie nesse local está de acordo com Esberárd et al. (1999), que cita sua ocorrência em depósitos, casas de bombas e porões.

Um exemplar de Rynchonycteris naso foi recolhido na região da Pampulha, e um de Tadarida brasiliensis foi coletado em uma residência na Regional Norte. A presença dessa espécie em residências foi relatada por Esberárd et al. (1999), referindo-se a telhados e forros.

\section{CONCLUSÕES}

Neste trabalho, os morcegos estão representados no município de Belo Horizonte por quatro famílias e 11 espécies. O tipo de ocupação humana influi na diversidade de morcegos observada em cada regional, seja pela disponibilidade de alimento ou pelo tipo de abrigo oferecido. Dentro de determinada área de degradação severa, os morcegos concentram-se em focos de área verde, que acabam atuando como "oásis", com diversidade inesperada de espécies. A época de ocorrência dos partos nos morcegos está relacionada à disponibilidade de alimento, mas admite-se a ocorrência de partos esporádicos durante todo o ano.

\section{AGRADECIMENTOS}

Ao Rodrigo Redondo, Marcelo Henrique Marcos e Fernando Perini, pela ajuda nas identificações; à profa. Sônia Talamoni (PUC-MG), pelo auxílio na busca de fontes bibliográficas; ao prof. Marlon Zortéa (Jataí - UFGO), pelo envio dos artigos.

\section{REFERÊNCIAS BIBLIOGRÁFICAS}

BAKER, R.J.; CARTER, D.C.; JONES, J.R. Biology of bats of the new world family Phyllostomatidae. Part I. Lubbock: Texas Tech., 1976. 218p.

BALANÇO hídrico de Belo Horizonte. Brasília: Ministério da Agricultura, 2000. Disponível em: $<$ http://masrv54.agricultura.gov.br/rna/climatolo gia/Dados/Balanco_hidrico/MG/Belo\%20_Horiz onte.htm>. Acessado em: 15 ago. 2002.

BREDT, A.; UIEDA, W. Bats from urban and rural environments of the Distrito Federal, midwestern Brazil. Chiroptera Neotrop., v.2, p.54-57, 1996.

CÉSARI, A. Análise de investigações sobre a presença de morcegos em habitações humanas na cidade de Belo Horizonte. In: CONGRESSO BRASILEIRO DE ZOOLOGIA, 21., 1996, Porto Alegre. Anais... Porto Alegre: Universidade Federal do Rio Grande do Sul, 1996. p.236. (Resumo).

DE KNEGT, L.V. Chiroptera (Mammalia : Chordatta) capturados em Belo Horizonte, Minas Gerais, 1999 a 2003. 2003. 69f. Dissertação (Mestrado em Medicina Veterinária) - Escola de Veterinária, Universidade Federal de Minas Gerais, Belo Horizonte.

DIAS, C.M. Estrutura de comunidades de quirópteros de três áreas verdes da região metropolitana de Belo Horizonte, Minas Gerais. 1995. 30f. Monografia (Bacharelado em Ecologia) - Instituto de Ciências Biológicas, Universidade Federal de Minas Gerais, Belo Horizonte.

DINERSTEIN, E. Reproductive ecology of fruit bats and the seasonality of fruit production in a Costa Rica Forest. Bioropica, v.18, p.307-318, 1986.

DUARTE, A.P.G. Aspectos reprodutvos de Akodon montensis (Rodentia, Muridae) e Artibeus lituratus (Chiroptera, Phyllostomidae) em áreas de mata no sudeste do Brasil. 2003. 52f. Dissertação (Mestrado em Zoologia) Pontifícia Universidade Católica de Minas Gerais, Belo Horizonte.

EMMONS, L.H. Neotropical rainforest mammals: a field guide. 2.ed. Chicago: The University of Chicago, 1997. p.52-292.

ESBÉRARD, C.E.L.; LUZ, E.M.; CHAGAS, A.S. Uso de residências para refúgios por morcegos no estado do Rio de Janeiro (Mammalia: Chiroptera). Rev. Bras. Med. Vet., v.21, p.17-20, 1999.

FALCÃO, F.C.; REBÊLO, V.F.; TALAMONI, S.A. Structure of a bat assemblage (Mammalia: Chiroptera) in Serra do Caraça Reserve, SouthEast Brazil. Rev. Bras. Zool., v.20, p.347-350, 2003. 
FLEMING, T.H.; HEITHAUS, E.R. Seasonal foraging behaviour of the frugivorous bat Carollia perspicillata. J. Mammal., v.67, p.660671, 1986.

HEITHAUS, E.R.; FLEMING, T.H.; OPLER, P.A. Foraging patterns and resource utilization in seven species of bats in a seasonal tropical forest. Ecology, v.56, p.841-854, 1975.

KUNZ, T.H.; DIAZ, C.A. Folivory by leaffractionation in fruit-eating bats, with new evidence from Artibeus jamaicensis. Biotropica, v.27, p.106-120, 1995.

KUNZ, T.H.; ROBSON, S.K.; NAGY, K.A. Economy of harem maintenance in the greater spear-nosed bat, Phyllostomus hastatus. $J$. Mammal., v.79, p.631-642, 1998.

MULLER, M.F.; REIS, N.R. dos. Partição de recurso alimentares entre quatro espécies de Morcegos frugívoros (Chiroptera, Phyllostomidae). Rev. Bras. Zool., v.9, p.345355, 1992.

SÁNCHEZ, M.M. Morcegos fitófagos urbanos: relações tróficas, estrutura e distribuição das espécies no campus universitário da Universidade Federal de Minas Gerais, Belo Horizonte, durante a estação seca do ano. 2001. 65f. Dissertação (Mestrado em Ecologia) Instituto de Ciências Biológicas, Universidade Federal de Minas Gerais, Belo Horizonte.

SAZIMA, I.; SAZIMA, M. Solitary and group foraging: two flower-visiting patterns of the lesser spear-nosed bat Phyllostomus discolor. Biotropica, v.9, p.213-215, 1977.

SILVA, J.A. $O$ papel dos quirópteros na manutenção do vírus rábico em Minas Gerais. 1996. 22f. Texto avulso (Disciplina de Problemas Especiais em Epidemiologia Doutorado em Ciência Animal) - Escola de Veterinária, Universidade Federal de Minas Gerais, Belo Horizonte.

SILVA, M.S.; HARMANI, N.M.; GONÇALVES, E.F.B. et al. Bats from the metropolitan region of São Paulo, southeastern Brazil. Chiroptera Neotrop., v.2, p.39-41, 1996.

TAMSITT, J.R.; VALDIVIESO, D. Reproductive cycle of the big fruit-eating bat, Artibeus lituratus (Olfers). Nature, n.198, p.104, 1963.

TAVARES, V.C. Ecomorfologia do vôo, dietas das espécies e composição de uma taxocenose de morcegos (Mammalia:Chiroptera) do Parque Estadual do Rio Doce, leste de Minas Gerais, sudeste do Brasil. 1999. 111f. Dissertação (Mestrado em Ecologia) - Instituto de Ciências Biológicas, Universidade Federal de Minas Gerais, Belo Horizonte.

TOLEDO, F.R.N. Manual para reconhecimento das árvores e arbustos do sistema viário de Belo Horizonte - MG. 1993. 30f. Monografia (Bacharelado em Botânica) - Instituto de Ciências Biológicas, Universidade Federal de Minas Gerais, Belo Horizonte.

UIEDA, W.; HAYASHI, M.M. Rã como item alimentar do morcego Phyllostomus discolor. In: CONGRESSO BRASILEIRO DE ZOOLOGIA, 21., 1996, Porto Alegre. Anais... Porto Alegre: Universidade Federal do Rio Grande do Sul, 1996. p.240. (Resumo).

VIZOTTO, L.D.; TADDEI, V.A. Chave para determinação de quirópteros brasileiros. Bol. Ciên. Fac. Ciên. Letras São José do Rio Preto, v.1, p.1-72, 1973.

WILLIG, M.R.; CAMILO, G.R.; NOBLE, S.J. Dietary overlap in frugivorous and insectivorous bats from edaphic cerrado habitats of Brazil. $J$. Mammal., v.74, p.117-128, 1993.

ZORTÉA, M. Folivory in Platyrrhinus (Vampyrops) lineatus. Res. News, v.34, p.59-60. 1993.

ZORTÉA, M. Reproductive patterns and feeding habits of three nectarivorous bats (Phyllostomidae: Glossophaginae) from the Brazilian cerrado. Braz. J. Biol., v.63, p159-168, 2003. 